\title{
DARG Report
}

What we must do is ensure we 'put our money where our mouth is' and provide the resources and expertise to make sure that training is professionally provided for the whole team and evaluated carefully
Mike Grace e-mail:m.grace.bdj@bda-dentistry.org.uk

\section{Veryone always knew that the Report of the Dental Auxiliaries Review Group (DARG Report) would be controversial, which is why the General Dental Council (GDC) allowed a six month consultation period. The response of the BDA to the report (announced on December 18 last year) has indeed created a stir in the dental world. With the time for responses from both professional and lay bodies now over, we must wait until May and the debate in the GDC - which promis- es to be interesting.}

In essence the DARG Report is about the development of the dental team and how this should be administered. While each group representing the different members of the dental team tends, understandably, to see the subject from its own point of view, the DARG Report tries to stand back and see the whole picture within both current and, hopefully, future changes in legislation affecting The Dentists Act.

The Review Group originally suggested a number of general principles. The first, and paramount, one is that patients must be protected and their needs come first, which we must assume everyone agrees with. The other principles are based around the statutory registration of all members of the team with the GDC, the expansion of permitted duties of current auxiliary personnel and the introduction of effective training for all members of the team. In response the BDA has produced what some might say is a radical approach. This contains two different philosophies from the DARG Report and it is these differences in perception between the dentists' view and the view of auxiliaries that is currently causing the controversy.

The first difference is that the BDA response suggests that it is not appropriate to have statutory registration for all members of the dental team. It suggests that registration is reserved only for members of the team who are involved in clinically invasive procedures (hygienists and therapists) or those who are unsupervised and have to exercise judgement in making decisions that could have a substantial impact on patient health and welfare. The second difference is the suggestion that the duties of auxiliaries need not be 'laid down' as specific tasks but could be variable and 'as prescribed by the dentist' as the occasion demanded, provided the auxiliary is appropriately trained. The BDA response suggests that statutory registration in dentistry should use the same principles that apply elsewhere in healthcare. Both these points seem to make sense from the perspective of the dentist.

However, the other team members find the DARG suggestions of registration for all team members and specific duties both more attractive and more realistic. They argue that registration gives patients more confidence and that specific duties are easier, and safer, to interpret.

The interesting thing is that if you try to stand back from the whole affair and see the matter as a patient might, then I feel the most important aspects of the development of the dental team are being neglected. Whether the future is DARG or BDA response (or something in between) matters very little to most patients. What does matter is that the people responsible for their oral health care are both competent and confident in what they do, whether that involves clinical treatment or management of the business. As a profession we are very good at training team members in basic sciences and clinical skills. We are less effective at training them to communicate, think, work and to develop as a team.

Both the BDA response and the DARG Report emphasise the importance of training and education. What we must do, whatever happens in May at the GDC debate, is ensure we 'put our money where our mouth is' and provide the resources and expertise to make sure that training is professionally provided for the whole team and evaluated carefully. A presentation on teamwork as part of a lecture course will simply not do. 